\title{
Interview
}

\section{In conversation with George Godber}

Hugh Freeman interviewed Sir George Godber at his home in Cambridge in April 1988.

HF Could I ask you about your first exposure to psychiatry in your medical training and how it struck you at that time.

GG Well, my first exposure came during my fourth year at Oxford, when I was doing pathology and pharmacology, in

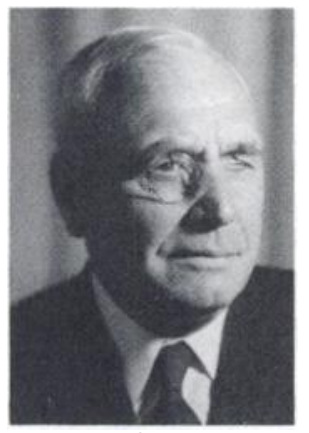
the six months of clinical work that we used to be able to do then. One of the regular things was that we went once a week to Littlemore Mental Hospital, out on the edge of Oxford, where we were taught after a fashion by the Medical Superintendent.

HF Was that Dr Good?

GG It was indeed Dr Good, and he just talked, and talked without really carrying a great deal of meaning to the people to whom he was talking. So I couldn't say that I got a very good impression of mental health there. I didn't have any more, of course, until I did my main clinical training at the London, and I wouldn't say that the training in psychiatry was very good there either. The psychiatrist who did the lectures and was the main teacher did take us to one or two mental illness and mental deficiency hospitals, but it was regarded by most of my fellow students, I think, as a not very onerous half day out. I don't think we got any real sympathy for psychiatry or for mental illness, and it didn't seem to figure very largely in what other teachers at the hospital were trying to give us.

HF After qualification, did you have any contact with psychiatric illness?

GG I didn't do any work in psychiatry - didn't do a job in a psychiatric hospital, for instance. I next came into contact with psychiatric patients when I was doing some work for the Ministry of Health in 1939, helping to prepare for the Emergency Medical Service hospital programme. This included visiting a number of mental illness and mental handicap hospitals to propose ways in which some of their buildings could be used for casualties, if indeed we had to use that number of beds for them. I encountered a number of senior psychiatrists then, but it was hardly an introduction to effective psychiatric work, because those hospitals were mainly of the custodial type. There are one or two people one remembers, like Macmillan at Mapperley, who was a very impressive personality, but I can't say that I got much else out of it.

HF Any particular aspects of the wartime experience which are of interest in this connection?

GG Not insofar as the management of mental illness is concerned because, as you know, a fair number of patients were crowded up or moved out of mental hospitals then, if any of their buildings were being used for the physically ill or military patients. But I did have some contact with this problem, because I was one of the teams of hospital surveyors who looked at all the hospitals in the country. As Regional Medical Officer for the Ministry, I did the survey of the North Midlands with Sir Leonard Parsons of Birmingham and Clayton Frye of Leeds. I was always puzzled by the way in which the mental hospitals were excluded from that particular survey. It was largely, I believe, because the Board of Control treated this as their separate empire, and if anything was to be done about provision for psychiatric illness, they thought that was within their compass; they didn't want the advice of these people from outside. And they could have been right about that, because I don't think any one of the three of us knew a great deal about mental illness.

HF Before the War, was there really any thought that things would change, so far as the treatment of mental illness was concerned?

GG I don't think I am in a position to answer that, because I only went into the Health 
Department in the early part of 1939 , and was almost straight in to the preparation of the emergency services. But there had been a certain amount of change in the general hospitals by then, in the introduction of more outpatient services, and I don't think we should forget that between the Wars, there was quite a lot of new building for the handling of early - cases. Many mental hospitals had good modern admission units, though some of the patients they were admitting would probably eventually graduate to one of the long-stay pavilions. There was some good accommodation in mental hospitals; it was the old and very inhospitable dumps that needed to be cut down.

HF In the discussions about a future health service that went on in the latter part of the War, what was the feeling initially about the place of mental and mental deficiency hospitals?

GG Nothing very positive. The management of services for mental illness was really passed by in much of the thinking. Yet it didn't seem practicable to devise a hospital service, certainly of the kind that was required by the 1946 Act, under which all the hospitals were going to be taken over, to organise a comprehensive health service without taking the mental hospitals into the same organisation. An argument went on about mental handicap, but there was really no-one else with whom that particular problem could have been left, with any degree of fairness to the mentally handicapped.

HF I think it's true, isn't it, that the first actual plan for the NHS excluded the mental hospitals from the general services?

GG I think that is true. I wasn't really involved in the detailed exchanges centrally, in the early .1940 s. One saw, of course, the published reports of the Medical Planning Commission and Medical Planning Research - that group of younger doctors - and I think that the general view of most doctors directly concerned with psychiatry was that the arrangements for the mentally ill would conform to the same pattern as the rest. In 1943, I was engaged in doing this hospital survey. One only became aware of the problems of linking up the mental hospitals with what was being done for the physically sick because of odd exchanges with the staff at the Board of Control, who were then responsible.

HF When the NHS was set up, all the mental hospitals and all the mental deficiency hospitals were given separate management committees. Do you know why that was?

GG I think it was largely at the insistence of the
Board of Control. They believed that only they had the requisite background, and that there should be people locally who had this special, isolated interest in mental illness or mental handicap to supervise those hospitals. There were attempts by some regional hospital boards to get the large mental hospitals incorporated in mixed groups, and some of those were referred back and altered at the insistence of the Ministry, because the Minister had to approve all grouping schemes. There was no reluctance locally to having mixed management groups - it was the Board of Control's influence.

HF Coming to the time after the establishment of the NHS, I suppose that what must have become clear to the Ministry was that there were very serious problems in the mental hospitals.

GG Yes, that's true. The line generally taken by the people on the Board of Control side, which now doubled with being the Mental Health Division in the Ministry, was that we needed more hospital beds than we had. The emphasis really was still on care within institutions, much more than on out-patient care, and it was only in odd places like the Marlborough Day Hospital that there existed real facilities outside for looking after people who were mentally ill. There were, of course, out-patient sessions, some of them at general hospitals and some not, but in the very early days there wasn't really forward looking promotion of out-patient care, short respite stay, and support in the community. There were a few people doing this, like T. P. Rees at Warlingham Park and Macmillan at Mapperley, who were trying to get across the idea that you shouldn't approach mental illness first with the idea of incarcerating the person suffering from it and trying to put him straight, away from the whole of his ordinary background. I think it was the Manchester Region, where you work, that really began to see the opportunity of providing short-stay units, day hospital, and outpatient care - chaps like Arthur Poole, who was established in Oldham before you went to Salford. I remember Poole well and Chalmers Keddie, the MOH with whom he worked, and being very impressed on visiting them with the way they were trying to do so much more for the mentally ill, without taking them out of circulation. And there were people like Joshua Carse at Graylingwell, whose 'Worthing - Experiment' was widely publicised. But it seems to me that too little credit is given as pioneers in this field to T. P. Rees and the $\mathrm{MOH}$ of Croydon, Dr Wright, who was very 
constructive, and was one of the youngest of the County Borough MOHs. The thing that always impressed me was that you got this progress going where you had support from community services. It wasn't something that just the psychiatrists were going to do, from the base of their mental hospital.

HF I think what you are saying is that these ideas started in the periphery, and then the Ministry became aware of them and perhaps began to change its thinking. Would that be true?

GG Yes, partly. But it was a subject that exercised the Standing Mental Health Advisory Committee right at the beginning. There were reports of a day hospital (an experimental one) in Montreal, and it happened that when I went on a WHO travelling fellowship to the United States and Canada in 1951, I was asked by Sir Alan Daley, the then County Medical Officer for London, who was Chairman of that Committee, if I would visit the place and report back. Along with John Pater, my administrative colleague, I went there and was very impressed by Ewan Cameron and by the work that he was doing; when I came back, I reported favourably on it to the Committee. They used that, I think, not as an original idea reported from North America, but as confirmation of the advantages that could be gained by this kind of approach. And they came out strongly in favour of development of day hospitals and short-stay care.

HF Apart from the Day Hospital in Montreal, did you see anything that impressed you particularly in North America?

GG Well, we were there for a specific purpose - to examine their programmes for training in administration in hospitals, and this was an incidental which I was asked to look at. I did see an enormous mental hospital outside Chicago from which I got one of the funniest comments I have ever heard from a medical superintendent. I was talking to him about his staff and what they did, and he said "Well, of course, I don't have much to do with the patients. I deal with the political end". I had got his figures about hospital administration and said "How on earth do you manage to admit 200 patients a month?" And he said "Oh, it's quite easy. We have so many escapes".

HF Did the Standing Mental Health Committee's ideas and pressure influence the Ministry's thinking very much?

GG Yes, they gave support to it, for example, in endorsement of the work that Carse was doing down in Worthing; I remember visiting Carse with Walter Maclay. The thinking of the very good people at the Board of Control - Rees
Thomas, Maclay, and Isobel Wilson - was clearly moved by this kind of experience, and their influence was important in getting the Ministry to look again at it. Then, it came largely into the work of the Royal Commission, which was considering mental illness and mental handicap from 1954. There was a good deal of public concern about some of the facts which were coming to light about the incarceration of the mentally handicapped, and about people who spent their whole lives in institutions, in spite of a capacity to contribute some practical service to the world outside.

HF In the early years of the NHS, was there any political interest in mental health, to try and improve the standard of services?

GG I think it was Iain MacLeod who managed to get Treasury agreement to the Mental Million that was supposed to be used to help rapidly in the development of better provision for the mentally ill. There were one or two examples of provision for the mentally handicapped too. I recall the Oxford Region, with which I had had pretty close links before I became Deputy Chief Medical Officer, converting a large hutted establishment into a new unit for the mentally handicapped.

That's not quite the same thing, though, as a different approach to the handling of the problem - a serious attempt to do something about a sector of the National Health Service that had been very much neglected. However, if you look at what was done by, for instance, the Manchester Regional Board in some of those really awful units that had been used for the mentally ill and handicapped, probably mixed together, in some of the public assistance institutions in the large Lancashire towns, that was a real advance. It was a change in the physical basis of treatment, which helped the better handling of patients so much, if they had to go in for short periods.

HF That was entirely a regional initiative?

GG Yes, I remember you going up to study it and asking me whether I really thought that this was a valid contribution to handling the mentally ill. I didn't claim any special knowledge of psychiatry, but I was convinced of its value, and Walter Maclay, who was my particular confidant on the subject in the Ministry, also became convinced of what could be done by this attempt to cut into what looked like an insoluble problem at an acute and early stage. We'd had something like that over tuberculosis, right at the beginning of the Health Service. There were long waiting lists for sanatoria, and because of that, people didn't necessarily get admitted at the beginning of 
their illness, when treatment might be most effective. That was deliberately reversed and, using the new anti-tuberculosis drugs, produced a quite striking change in the outlook for tuberculosis; it stopped people from ever becoming chronic or advanced cases. I remember talking to Walter about the possibility of going for mental illness in much the same way.

HF Do you remember roughly when that was?

GG I should think it was about 1956. I remember that Walter wrote a section for the Chief Medical Officer's Annual Report in 1958, which presented a thesis for a future of that kind. But of course, the thing was already happening under our eyes, except that it sometimes takes a long time to see. You will remember the Tooth and Brooke paper about changes in the mental hospital population. I know that the reduction in numbers was facilitated by the drugs that were becoming available, but what the drugs were doing was letting psychiatrists get into real contact with the mentally ill, at a time when something more could be done about it. It became practicable for them to live in the community, given family support.

HF I suppose that in the mid 1950s, people were still making plans for new mental hospitals, assuming that something like the same pattern as before would be repeated.

GG That is quite true. I have a particularly vivid memory of one in the Birmingham Region. At Bosford, where the indoor athletics take place, there was a hutted establishment, on a site which was already owned by the Regional Hospital Board, which had been planned for a mental hospital before the War. The Board had been promised by Ministers that they would be allowed to go ahead with this, as one of the earliest of the hospital building schemes. But it seemed to me quite ludicrous to have a policy of providing acute early treatment at general hospitals, and then to go out and build another large mental hospital in the countryside. The reaction in the Ministry was "Yes, we know all that, but Ministers have been committed to this for years, and if we go back on it, there'll be hell to pay". So I offered to go and try to convince them, and with Isobel Wilson and an administrative colleague, met the Regional Board. We put the idea to them that instead of having this one new mental hospital, they should think of the four general hospitals that were in the catchment area, and consider whether they couldn't rather provide an acute psychiatric unit at some or each of those. At the end of about an hour and a half of discussion, the Chairman of the Board said "Well, you see, we don't agree with you. What are you going to do? Give us a direction". And I gave the answer that I had been authorised to give if I couldn't persuade them, and said "No, it's your job - it's your mistake if you make it, and you've got to live with it". So they looked a bit surprised and said "Well, thanks very much", and we had lunch and all went home. About a couple of months later, I got a letter from the Chairman, saying that they'd really been convinced, and were not going ahead with the new mental hospital.

I'm not giving you that as an example of how I was clever - I was simply the channel through which the idea was being communicated. But people were persuadable;they simply needed the argument deploying, just as one had had to go some years before to a Regional Board and say "Look. You don't want to put your hospital building resources into a new sanatorium. We aren't going to need sanatoria by the time you've got that one built". But to do this, you've got to carry conviction with the local people, about the service they are going to have to provide.

HF By then, the Ministry itself was convinced that there would be no further mental hospitals on the traditional pattern?

GG Oh, yes. After that epsiode, I don't think there was any prospect of anybody building another of those large establishments. They had sometimes been described as being simply personal estates of medical superintendents.

HF There was, I think in 1953, a report by an Expert Committee of WHO on The Future of Mental Health Services, which was a surprising far-looking document. Do you recall that it had any influence on thinking in the Ministry?

GG It certainly did. There were two British people in that Committee, I believe. It was certainly read in the Ministry and seen as a possible blueprint for the future. But you know, in a Health Service like ours, you can't say "It shall be thus and thus", and the Regions are going to do it. You've got to carry conviction to the country with your policies.

HF From the time it was decided that there were to be no more new mental hospitals presumably Ministry thinking was in the direction of basing psychiatric care increasingly in general hospitals and in other extra-mural services. But can you say if there was a point at which it was decided that the existing mental hospital system would actually have come to an end?

GG Well, you may remember the Annual Meeting of the NAMH which Enoch Powell addressed. He had just seen the Tooth and Brooke paper, which said that the long-term mental hospital population was going down, and it really was 
happening on a very considerable scale. That did have a very considerable impact, because his presentation, as has been shown in other fields, can be very incisive.

HF Would you say Enoch Powell's 'water tower' speech represented the thinking at that time, or had he gone rather ahead of your planning then?

GG I would say that he was reflecting the Ministry thinking at the time, but he was giving it publicity in a way that really took us aback. When he'd done it and got away with it, that was fine, but civil servants tend to be a bit nervous about how to handle the public. It's the politicians who know how to do that. I wouldn't say that he was by any means ahead of his Ministry's thinking when he did that; it was just that he knew the moment to present it and we did not.

That brings me to something else. One of the things that happened in the Health Service generally from 1952 on was that there was control of consultant establishments. Everybody was asking for more psychiatrists, because the specialty was far too small for the number of patients who had to be handled. I had to chair the Central Advisory Committee on consultant establishments, and we were quite determined that the relatively small annual number of trained psychiatrists should go to the places where they were properly used. So the Region that just proposed one extra psychiatrist in a hospital with a thousand or more beds, which perhaps had two or three consultants and no real plan to handle the problem as it was now beginning to be handled, so as to get people back into the community - they didn't get their extra consultant.

HF The Powell speech was followed the next year by the Hospital Plan. It seems to me that the Hospital Plan is really the first time that you see in official documents the idea that there would be psychiatry throughout the country in district general hospitals. Is that right?

GG I think it's the first presentation of a comprehensive plan for doing it that way, but remember Walter Maclay's 1958 essay. The Hospital Plan was again an Enoch Powell initiative. The idea of setting about this, region by region, was being worked out when he came to the Ministry, but what Enoch did was to say, "The way to get this over is to put it together so that we can go to the Treasury for the resources that we're going to need, and for us to publicise what we are trying to do". He knew very well that this Five-year Plan, to roll forward and be revised regularly, could be wrong in the first presentation; it would have to be adjusted. But at least it was giving us something to adjust, instead of just doing bits and pieces here and there. Every Region had got to produce its own plan, subject it to Departmental scrutiny, and then a national report was produced, which was very much Enoch Powell's personal responsibility. He sat through all the preparatory meetings of that Report and, perhaps even more important, said at the end of it "Alright. We've done that. Now what about the Health and Welfare Services? Because one is useless without the other". And the plan that was produced the following year to develop those services is, of course, the indissociable corollary to a hospital service. Health care for a community isn't just what we do in institutions; it's what is done in collaboration between the services, inside and outside. I think that the Health and Welfare Plan, though it was not revised and up-dated in the same way as the Hospital Plan, was just as important. It made the local health authorities look at what they were doing and if they weren't doing something in, for instance, the mental health field, they had to go back and show what they were going to do.

HF The criticism has been made of the Hospital Plan that its financial basis was not wholly realistic, and that to do everything that had been proposed would have cost far more than was likely to be available.

GG That's quite true, because the cost of hospital building was going up and up, but that was a five-year plan, to be rolled forward year by year. So if you look at it as the first stage of a process, and not a definitive or final plan, it was the right way to do it. When Kenneth Robinson came along, he revised it of course, but really what he did was to up-date the Plan as it originally had been imagined it would be up-dated.

HF Going back to the question of mental hospitals. From, I suppose, the late 1950 s, it was clear that they were not going to expand or be developed, and from the Powell speech, it was clear that they were going to be very much reduced, but was there at any point a conscious decision that they would eventually disappear?

GG I think that you were not quite right when you said they were not going to be developed, because that reflects much of people's attitude toward care for the mentally ill at the time by suggesting that development meant physical expansion. It didn't; it meant contraction, concentration, and integration with what was being done in the community. True, that means that your big hospital has fewer and fewer beds, though it may have more and more psychiatric staff, medical and other, do more 
work, and look after more and more patients. Eventually, as you make different arrangements for the relatively small number of patients in long-stay care, you do the logical thing and pull back to the District General Hospital unit. But it's a stage-by-stage process.

HF Was that thought of then, as likely to happen in the very long term?

GG Yes, Well, we've had the very long term, haven't we? After all, you and I are talking nearly 30 years after the original Hospital Plan.

HF But I'd like to press you a bit further on this point. Did people in the Ministry at that time who were thinking ahead - did they see a time when there would be virtually no mental hospitals?

GG Not mental hospitals as we'd known them. There might well be places which would have to be under continuing medical oversight, with nursing support, that might be called something else. They'd serve the same function, only a great deal better than some of the pavilions of the old mental hospitals. In psychogeriatrics, obviously there were going to be relatively long-stay patients - some of them are going to stay a few years or more, because their dementia is going to end only with their death.

HF Looking ahead from that point, therefore, there would have been a vision of acute psychiatric care based in district general hospitals and a network of community services. Now, that would involve first of all very great development of staff training, the employment of many new staff, and, of course, of capital spending on new facilities. When you added up the whole, it probably came to a huge amount of public spending. Were planners confident that it would be possible to do that?

GG I don't think people were confident that it would be possible to produce a large number of new buildings, but from the very beginning, in all respects, not just in the mental health field, the Health Service has had to operate against that type of background. It's what you do more than the property that you have that determines the outcome of health care. You were making the point that there had to be much better developed caring staff in the community to work with those who were institution-based. It's the people that matter a great deal more than buildings, provided the buildings are reasonably human and not those awful old establishments that you and I knew 30 and 40 years ago.

HF Could I ask you next about the various Minis- ters that you have known, and you have known many. Obviously I suppose, their attitudes to mental health will have varied a great deal. Some, perhaps, would not have thought about it very much. Could you pick out any particularly influential Ministers?

GG Well, I don't suppose it's fair from the medical civil servant's point of view to criticise or commend Ministers in detail. I think Bevan was interested, but I don't think he was deeply informed about it. Iain Macleod was well aware of its importance. I remember particularly him saying that this was the great problem in the Health Service - the management of the mentally ill. He was then, after all, up against a service that thought only in terms of custodial care. This was only at the beginning of the period when we had some psychotropic drugs, and there were only a few psychiatrists of the T. P. Rees or Macmillan turn of mind, who were trying to handle mental illness differently. So what he could see was the rather appalling physical accommodation we provided for the mentally ill in those days, and he tried to supplement this, to minimise overcrowding.

Dennis Vosper didn't have very long as Minister, because of his own illness, but he was concerned about mental health and I think he would have put a good deal of effort into it. Derek Walker-Smith was involved with the passage of the Mental Health Act, after the Royal Commission, and he felt that this gave an opportunity for a substantial move forward, as it did of course. It reduced the incarceration element of the care of the mentally ill dramatically. Then Enoch Powell came along, and he was for doing things for the mentally ill by active intervention, as he was in the hospital service generally, and also for ensuring that community services were properly developed. I suppose Kenneth Robinson's sympathetic relationship with the mental health services of his time as a former member of the North West Metropolitan Regional Hospital board and Chairman of their Mental Health Committee was specifically important. He had a more direct acquaintance with the service when he started, and a feeling for it. Dick Crossman saw that mental illness and mental handicap were both fields where we needed to make more rapid progress. He had a pretty high profile and started the Hospital Advisory Service to press things forward. He was very shaken by that inquiry in South Wales into the episode in the mental handicap hospital, and he tried to get something done. I don't know whether it was a personal interest of Dick's, but he saw 
his job as a Secretary of State as one that required intervention in this area, as did Keith Joseph. I remember accompanying Keith on a visit to one of the mental handicap institutions in the North West Metropolitan Region, and he was very anxious to see more done. In his case, I think it was a consciousness of a problem, more than the kind of personal concern that some others involved have had, but he tried to get something done and to get extra resources into that field. That, of course, ends my direct contact with Ministers.

HF Going back to the Royal Commission. Do you recall exactly how and why it was set up?

GG I think it followed some of the public reaction to the long-stay retention of mentally handicapped people. There were some people who spent their whole lives in mental handicap institutions and need not have done so, if we'd made reasonable alternative provision for them in the community. It was curious the way those institutions became little, cut-off towns of their own, where the ablest people helped in the kitchen or laundry, rather than being prepared for going outside and living lives of their own. That was a factor, but the main factor was the perceived need to do something more about dealing with mental illness in its early stages, as well as general public reaction against certification and compulsory consignment of people to institutions behind walls.

HF Was there any particular individual who was influential in the decision to set up the Commission?

GG I don't think I could put a finger on any particular person. I was then DCMO. The people with whom I had most to deal were those on the Board of Control: Rees Thomas, Walter Maclay, and Isobel Wilson. They were influen- . tial in the Ministry, of course - Percy Barter was the Chairman of the Board. I don't think I'd be a suitable person to pick out names on that.

HF Were the Board of Control themselves favourably disposed toward the Commission?

GG I think they were, yes.

HF Are there any further thoughts on this whole story, that you have, looking back from today's perspective?

GG I think that the Health Service has had less credit than it deserves for the speed at which it introduced reform in the handling of mental illness. Other countries may have gone further than we have done since, but we were early in the field of trying to handle the problem by acute treatment and community care. I think we could claim to have exploited the initiatives of people like Rees, Macmillan, Carse, and
Poole - and you were in that initiative yourself-as well as some people in other countries, like Cameron in Montreal and Querido in Amsterdam.

HF From your account, it sounds as though most of the new ideas came from doctors, and this is interesting because doctors are often put in the position today of being the obstacles to progress. Do you think that doctors did in fact play the key role?

GG I think initiatives have come from doctors, but that the push for wider development came from others who were convinced by them. Because I haven't mentioned their names doesn't mean that they weren't at least as important as some of the medical figures. My contacts were medical, but the NAMH was the public crusading body, much more than the RMPA. I would have said it was the more progressive group of the two.

HF Have you any particular memories about the foundation of the College? I remember you were at the first public dinner, when the College was founded. Were you involved in these negotiations at all?

GG Well, if you're Chief Medical Officer, you can't avoid having contacts with that sort of thing and indeed, you wouldn't want to avoid having them, but I think it would be entirely wrong to pretend that I was in any way responsible for that change. The people concerned, like Martin Cuthbert and Ben Monro, would come and talk to me about what to do. I'd hear about questions that arose over the Charter and that sort of thing, because it was a Royal Charter and raised important issues. But I suppose in a very minor way, I could have been an honest broker, and I must say I was very surprised and greatly honoured to be made an Honorary Fellow of the College in its early days. I knew well people like Martin Cuthbert, who ran a very good hospital incidentally, Martin Roth, and Aubrey Lewis, while Denis Hill particularly was my friend amongst the psychiatrists. So my position was only that of being a friend of the people who were actually doing things, and occasionally being in the position of giving a helping hand.

HF The College had a very sticky initial progress at some points - there was a fair amount of opposition-if not on the surface, then behind the scenes, wasn't there?

GG Yes. But then the old Colleges are always jealous of any newcomer. They were just the same over the establishment of the College of General Practitioners. We're very slow to move in medical organisations, and the medical establishment is a particularly conservative one. 
HF Have you any comments on individuals in the mental health field - I suppose we should avoid those still living.

GG I've mentioned T. P. Rees; he was the person I think who really made an early impression on me. There was Jack Rees, and Ronald Hargreaves, who had been with WHO. I have mentioned Walter Maclay - I think he gets less credit than he ought to have - he was a very important and benign influence behind the scenes. Macmillan I knew well, of course, from when I was in Nottingham in the early part of the War; again, a man for whom I had a very high regard. And of course there was Aubrey Lewis, with all his intellectual qualities, but I suppose amongst the psychiatrists of whom I have the pleasantest recollections is Denis Hill who set up, after all, the first department in a London teaching hospital, and breaking into them was no easy matter. His was the first London Chair, but he had predecessors outside London, of whom I knew best Bill Trethowan. Then I have mentioned that group of whom you were one-Poole and others in the Manchester Region, who I've always looked on as pioneers who haven't had enough recognition. There was Tredgold at UCH, who was the Regional Psychiatrist for the South East Metropolitan Region - a very nice man.

HF Yes. I succeeded him as Editor of Mental Health, which was the NAMH's journal.

GG Another person who perhaps ought to have a little credit and doesn't get it is Sir Alan Daley, who was the County Medical Officer of London. As I said, he was the first Chairman of the Standing Mental Health Advisory Committee, and an interesting chap. He was able to take on board some of the needs of psychiatry and hold the balance between the warring elements in that Advisory Committee. They were warring, I can tell you, so I think he ought to be in the 'gallery'.

\section{Physician liability for treating mentally incompetent patients}

\section{The views of one American lawyer}

\section{Allan B. Morrison*}

The issue of the rights and obligations of those involved in doing research on patients who are incapable of giving their consent to treatment is a difficult one. This difficulty is reflected in the papers and discussion which form the basis of the book Consent and the Incompetent Patient: Ethics, Law and Medicine (eds. S. R. Hirsch \& J. Harris) ${ }^{1}$ and that were the subject of the conference that led to it. Had I been in attendance, I am sure that I would have gained insights not available from the printed version on which I have had to rely. Nonetheless, I have sufficient sense of the proceedings to see where there are

* Mr Morrison is a practising lawyer in the United States. He is the director of the Public Citizen Litigation Group, a public interest law firm which he co-founded with Ralph Nader in 1972. He also lectures at both Harvard and Columbia Law Schools. areas that an American view, or at least the views of one American lawyer, might be of interest.

There are two important caveats for the reader. First, a reminder about American law. Under our system, there is not one answer to most questions of law, especially those having to do with issues of negligence or battery, because the law in those areas is established by each of the 50 states, rather than by the federal government. Thus, while there are many issues on which the states are quite close, there are others on which there are several different views which make it impossible to give an 'American' answer to a legal question. And given the novelty of this question, there is clearly no single American answer, in part because most states have yet to address the issue at all.

Second, although I have been practising law for more than 20 years, the subject of this book is 